\title{
Numerical analysis and simulation of the heat recovery from wastewater using heat exchanger
}

\author{
Timea Gabor*, Ancuta-Elena Tiuc, Ioana Monica Sur, and Iulian Nicolae Badila \\ Technical University of Cluj-Napoca, Department of Environmental Engineering and Sustainable Development Entrepreneurship, 103- \\ 105 Muncii Avenue, 400641, Cluj-Napoca, Romania
}

\begin{abstract}
The problem of global warming and the reduction of energy consumption have led to an evolutionary progress of research directed towards finding as many solutions as possible to these environmental issues. Firstly, this paper presents the background information on the role of wastewater as a source of heat for the future. Next, the paper includes the analysis elements that define a system for recovering thermal energy from wastewater. The main objective was to identify the parameters that determine the heat transfer. It has started from a conceptual model of the technological system that involves inputs and outputs characterized by technological, physical-chemical, measurable or imposed properties. In the second part this paper presents a numerical model elaborated for the analysis and simulation of the main physical processes, the mass and heat transfer, which underlie the operation of the heat pipe heat exchangers (HPHE). The numerical simulation of heat and mass transfer in the HPHE is computed by using Delphi 7 solver program. This program contained a series of sub-programs for the meshing of the field occupied by the HPHE, another subprogram for solving the meshing equations and the third for post processing. The design of HPHE is the key to provide a heat exchanger system to work proficient as expected. Finally, the result is used to optimize and improving heat recovery systems of the increasing demand for energy efficiency in residential buildings or industry.
\end{abstract}

\section{Introduction}

One of the secondary energetic resources that on which a greater accent has been put worldwide are wastewaters (liquid waste). Wastewater from all sources except toilets, enters the sewage system at a relatively high temperature and with an exergy content $[1,2]$. Clearly, the heat content of wastewater is a major loss source, so it must be addressed as a solution to reduce energy consumption in both residential and commercial buildings [3]. The potential for domestic wastewater recovery is quite high, approximately $3.5 \mathrm{kWh}$ of energy / person / day, which could be capitalized and used directly in several areas. [2]

The recovery of secondary energetic resources and of liquid waste with high energetic content also led to the development and implementation of various types of heat exchangers and heat recuperators $[4,5]$. Heat exchangers are widely used in the industry, transportation, constructions, thermal power plants, heating and air conditioning systems, electronic equipment. In all these applications, improving the efficiency of heat recovery can lead to substantial reduction of costs of production and use. The research is oriented in this direction aim in particular at selecting the work fluid with high thermal conductivity and how to direct the flow towards the surfaces destined for the actual heat transfer $[6,7]$.
The current paper presents results of research obtained from simulation and numerical analysis of heat recovery from wastewater using a HPHE.

The paper describes the physical mathematical model, establishing the system of governing equations, initial and limits conditions. It also presents the numerical model associated to the mathematical model and numerical methods of discretization when solving the differential system of equations underlying the mathematical model.

Simulation of thermal transfer is conducted for a liquid-liquid type heat exchanger, where heat pipes operate on the principle of phase change of the work fluid. $[8,9]$

Worldwide there are a series of papers that deal with theoretical and experimental research of the physical processes associated with the various types of heat exchangers, and more recently a great emphasis is placed on the use of numerical models [10-12].

Numerical models used for the analysis and optimization of mass and heat transfer processes between work fluids in heat exchangers are less costly than experimental research [13]. But it is important to note that these numerical models are improved based on the results of experimental research [14-17].

\footnotetext{
*Corresponding author: timea.gabor@imadd.utcluj.ro
} 


\section{Analysis and modelling}

\subsection{Description of the experimental equipment}

The heat exchanger used for experimental research (Fig. 1) was equipped with 40 heat pipes from S.C. EnergiQ Indco S.R.L Cluj-Napoca, with the following characteristics: outside diameter $10 \mathrm{~mm}$; length 1390 $\mathrm{mm}$; working fluid: refrigerant occupied approximately $20 \%$ of the total volume of the heat pipe at the vacuum at $10^{-8}$ Torr.

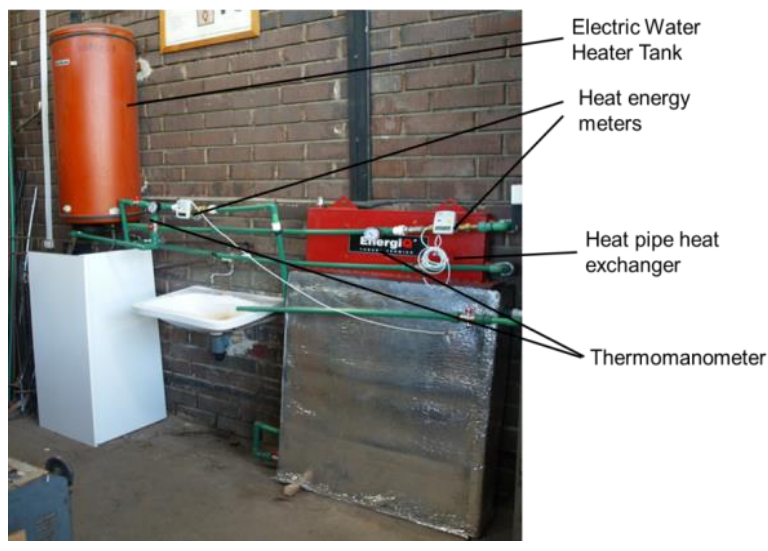

Fig. 1. The experimental equipment.

The heat exchanger was divided in two compartments (Fig. 2) - the lower one destined for the warm wastewater and the upper one destined for the cold water from the network, which is to be preheated. To these are added the outer wall and partition wall between the two compartments.

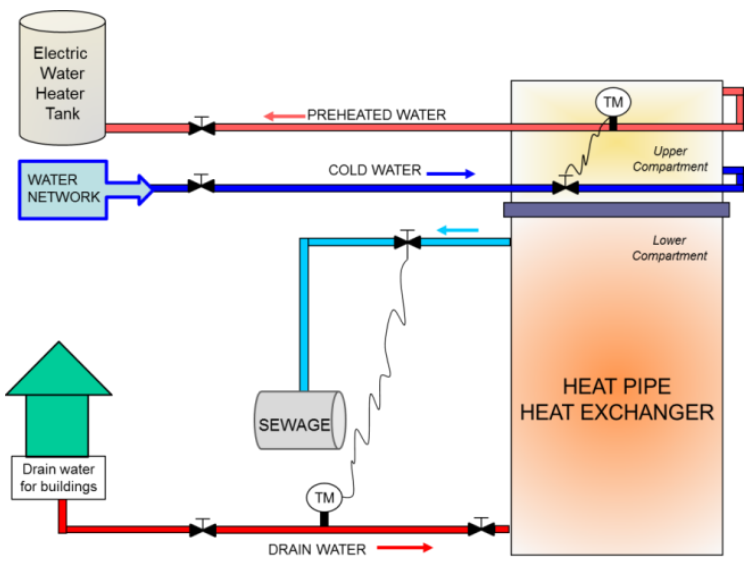

Fig. 2. Schematic diagram of the experimental equipment.

The upper compartment is provided with a horizontal flow divider, thus increasing the time interval in which the main flow of cold water is in contact with the heat pipes. The heat exchanger occupies a range that is approximated by parallelipipedic cells having the $d x, d y$ and $d z$ sides, in number of im $\mathrm{x} j m \times \mathrm{km}$, where $i m, j m$ and $\mathrm{km}$ are the number of cells in the direction of coordinate axes $O x, O y$ and $O z$.

In Fig. 3 is represented a horizontal section parallel with the $x O y$ coordinate plane. The 40 heat pipes are represented into two parallel lines. The wall of the heat

pipes is approximated also with parallelipipedic cells, with a volume $V_{\text {cell }}=d x d y d z$.

00000000000000000000 00000000000000000000

Fig. 3. Horizontal section parallel with the $x O y$ coordinate plane.

The flow of wastewater and water from the network is treated as a viscous flow, and the heat transfer at the interface between the heat pipes and water is achieved through conduction. Within the domain occupied by water, the heat transfer is achieved through both conduction and convection.

The structure of the water flow in cavities equipped with heat pipes is complex, mainly because of the occurrence of stationary vortexes above or laterally to the pipes, or of stagnation areas downstream of the pipes. These influence the heat transfer; vortexes contribute to the increase in efficiency of the local heat exchange, while the stagnation areas inhibit the heat exchange. $[12,18]$

\subsection{Governing equations for the system}

In the $x O y z$ Cartesian Coordinate System we have the equations of the numerical model, based on fundamental physical principles, expressed by the relationship of conservations laws for movement quantity - Navier Stokes equations (1-3), mass - continuity equation (4) and heat - Fourier equation (5) [19-21]:

$$
\begin{aligned}
& \frac{\partial \rho u}{\partial t}+\frac{\partial \rho u u}{\partial x}+\frac{\partial \rho v u}{\partial y}+\frac{\partial \rho w u}{\partial z}=-\frac{\partial p}{\partial x}+\frac{\partial}{\partial x}\left(\mu \frac{\partial u}{\partial x}\right)+\frac{\partial}{\partial y}\left(\mu \frac{\partial u}{\partial y}\right)+\frac{\partial}{\partial z}\left(\mu \frac{\partial u}{\partial z}\right) \\
& \frac{\partial \rho v}{\partial t}+\frac{\partial \rho u v}{\partial x}+\frac{\partial \rho v v}{\partial y}+\frac{\partial \rho w v}{\partial z}=-\frac{\partial p}{\partial y}+\frac{\partial}{\partial x}\left(\mu \frac{\partial v}{\partial x}\right)+\frac{\partial}{\partial y}\left(\mu \frac{\partial v}{\partial y}\right)+\frac{\partial}{\partial z}\left(\mu \frac{\partial v}{\partial z}\right) \\
& \frac{\partial \rho w}{\partial t}+\frac{\partial \rho u w}{\partial x}+\frac{\partial \rho v w}{\partial y}+\frac{\partial \rho w w}{\partial z}=-\frac{\partial p}{\partial z}-g \rho \beta\left(T-T_{0}\right)+\frac{\partial}{\partial x}\left(\mu \frac{\partial w}{\partial x}\right)+\frac{\partial}{\partial y}\left(\mu \frac{\partial w}{\partial y}\right)+\frac{\partial}{\partial z}\left(\mu \frac{\partial w}{\partial z}\right) \\
& \frac{\partial \rho}{\partial t}+\frac{\partial \rho u}{\partial x}+\frac{\partial \rho v}{\partial y}+\frac{\partial \rho w}{\partial z}=0 \\
& \left(\frac{\partial \rho c T}{\partial t}+\frac{\partial \rho c u T}{\partial x}+\frac{\partial \rho c v T}{\partial y}+\frac{\partial \rho c w T}{\partial z}\right)=\frac{\partial}{\partial x}\left(k \frac{\partial T}{\partial x}\right)+\frac{\partial}{\partial y}\left(k \frac{\partial T}{\partial y}\right)+\frac{\partial}{\partial z}\left(k \frac{\partial T}{\partial z}\right)
\end{aligned}
$$

where: $u, v$ and $w$ are components of the velocity vector; $\mu$ is dynamic viscosity; $x, y$ and $z$ are independent variables in the $x O y z$ system; $T(x, y, z, t)$ is temperature; $k$ is the thermal conductivity coefficient; $T_{0}$ is the reference temperature, in this case the wastewater or cold water input temperature; $\beta$ is the thermal expansion coefficient; $c$ is the specific heat at constant pressure.

For the control the advence of the free surface of the liquid used the equation of the volume fraction (6).

$$
\frac{\partial f}{\partial t}+\frac{\partial u f}{\partial x}+\frac{\partial v f}{\partial y}+\frac{\partial w f}{\partial z}=0
$$


where: $f(x, y, z, t)$ is the volume fraction function, if in point $(x, y, z)$ there is liquid it is equal to one and if there is no liquid it is equal to zero. [22, 23]

\subsection{Numerical model}

During the discretization of the numeric modeling, the differential equations from VOF were used [18, 22, 23]. A horizontal section of the discretization cells applied to the heat pipes is sketched in Fig. 4. Inside the discretization network, cells colored in blue indicate the pipe's wall.

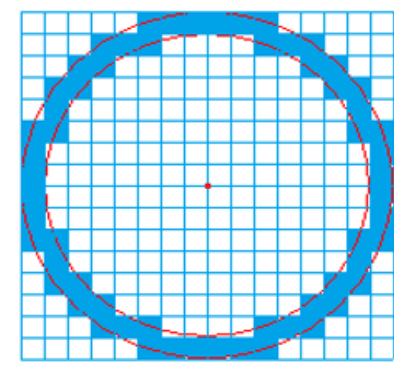

Fig. 4. Horizontal section of a heat pipe, parallel with the $x O y$ coordinate plane.

The current cell with the central point $P$ is presented in Fig. 5. Neighboring cells have centers $N, S, W, E, B$ and $T$ (red dots), and faces of the current cell have centers $n, s$, $w, e, b$ and $t$. Thus, in the positive direction of axis $O y$ noted with $E$, is the center of the neighboring cell and center of the face in point $e$. In the negative direction of axis $O y$ is the center of the neighboring cell in point $W$, and center of the face in $w$. So are the analogs in the direction of axes $O x$ and $O z$. For the entire cell, the main characteristic is point $P$, being treated as a representative point of dimensions $\rho, p, T, c, k$ and $\mu[19,20]$.

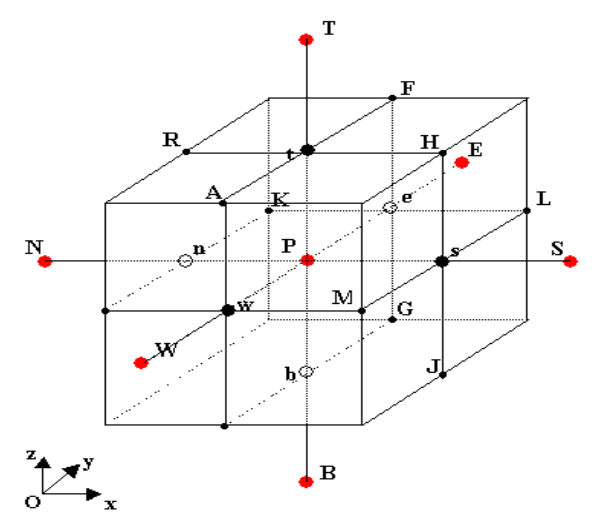

Fig. 5. Current cell $P$, represented with notations used for face centers and neighboring cells centers.

A parallel section to plane $y O z$ is presented in Fig. 6 . It passes through the center of the current $\mathrm{P}$ cell and its neighbors, representing the notations and associated grid points; the notations are those used by Patankar [20]. Components of the speed vector are defined in central points of the faces of the current cell, from axis $O y$ in $w$ and $e$, and from axis $O z$ in $t$ and $b$. It can be observed a cross grid formed by the central points and face centers. The grid points for the $v$ component, by axis $O y$, are on the faces parallel with plane $y \mathrm{Oz}$. An advantage of the cross grid is the fact that mass flows passing through the faces of the cells can be calculated without interpolation of the speed vector components (Fig. 6).

The parallelepiped centered in point $e$ having the rectangle $t c d b$ as vertical section parallel to $y O z$, will be the control volume of the v components $(i, j, k)$.

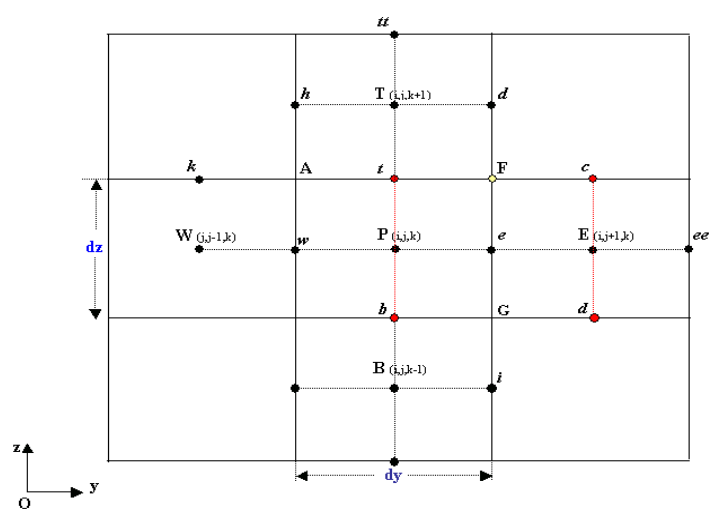

Fig. 6. Vertical section, parallel with plane $y O z$, through the center of current cell $P$ and its neighbors.

A horizontal section through the center of the current cell $P$ and its neighbors shows the arrangement of the speed components, $u$ and $v$, in the cross grid, being represented in Fig. 7.

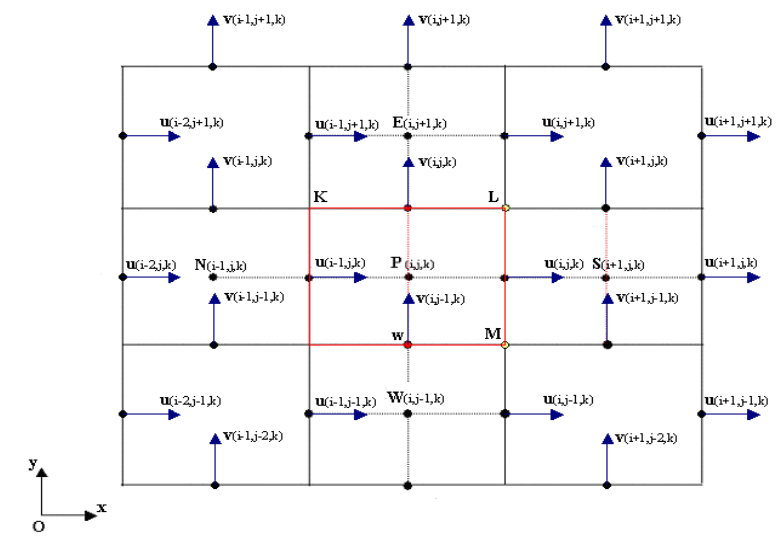

Fig. 7. Horizontal section through the center of the current cell $\mathrm{P}$ and its neighbors, indicating the arrangement of $\mathrm{u}$ and $\mathrm{v}$ components in cross grid.

Due to the fact that network cells can contain various materials, it is required the control of cell content, thus an additional variable was introduced in the form of a tridimensional matrix.

The elements of the variable are noted with $o b s[i, j, k]$, $(i, j, k) \in\{1,2, \ldots, i m\} \quad x \quad\{1,2, \ldots j m\} \quad x \quad\{1,2, \ldots, k m\}$, its component for the current cell will have values from one to nine. Their content is further specified:

$o b s[i, j, k]=1$ for cells that contain wastewater in the lower compartment, or cold water from the network in the upper compartment;

$o b s[i, j, k]=2$ for the cells that are partially full with wastewater in the lower compartment, or cold water from the network in the upper compartment; 
$o b s[i, j, k]=3$ for interior cells from the two compartments and that contain air;

$o b s[i, j, k]=4$ for cells outside the shape that contain air; $o b s[i, j, k]=5$ for cells in the supply section of wastewater or cold water;

$o b s[i, j, k]=6$ for cells in the evacuation section of the wastewater of heated water;

$o b s[i, j, k]=7$ for cells in the outer wall, divider wall between compartments and flow divider wall in the upper compartment;

$o b s[i, j, k]=8$ for cells in the heat pipe wall;

$o b s[i, j, k]=9$ for cells inside the heat pipes.

Next, there was conducted the temporal discretization using an Euler scheme assumed with the time step $d t$. The time step is variable and is determined in such a way that conditions of numeric stability to be satisfied. It integrates the basic equation system on cells in the network in a way that differs by the usual developments in Taylor series that are applied in the classic finite differences methods [21, 24]. The integration of the differential equation with a dependent variable $\Phi \epsilon\{u, v$, $w, T, p\}$ leads to an equation in the form:

$$
a_{p} \Phi_{p}=a_{0} \Phi_{0}+a_{E} \Phi_{E}+a_{w} \Phi_{w}+a_{T} \Phi_{T}+a_{B} \Phi_{B}+a_{S} \Phi_{S}+a_{N} \Phi_{N}+b
$$

where: $a_{0}=\rho_{0} V_{0} / d t$, and $V_{0}$ and $\rho_{0}$ are the volume and density of the cell in point $P$ at the previous time step, and $d t$ is the dimension of the time step. Coefficients $a_{E}, a_{W}$, $a_{T}, a_{B}, a_{S}$ and $a_{N}$ contain the sum of advective and diffusive contributions of the neighboring cells (Fig. 5). The diffusive component that was used has the general form $\Gamma f A / D n$ where $\mathrm{A}$ is the area of the common face between the current cell and its neighbor, and $\mathrm{dn}$ is the distance between the centers of the two cells. The exchange coefficient at the interface between cells, $\Gamma f$, is calculated as an arithmetic mean for density and viscosity, and as a harmonic mean for temperature values in the neighboring central nodes. When calculating the advective component it's used an "upwind" type interpolation which leads to a coefficient in the form of $\rho A \max (0, v)$ where $\mathrm{v}$ is the component of the speed vector that is perpendicular on the interface between cells $[19,20]$.

The system of the mesh equations for the movement quantity conservation (1-3), continuity equation (4) and heat equation (5) are solved in an iterative manner.

The Fourier equation (5) can be solved independently, but the continuity equation (4) and movement quantity equations (1-3) must be solved simultaneously. For the latter, is used the SIMPLE (Semi-Implicit Method for Pressure - Linked Equations) method, which simultaneously solves equations (1-4) using pressure and speed corrections.

Discretization the continuity equation (4) and movement quantity equations (1-3) we obtained (8) equation what is the standard discretization form of the Eq. (2) of movement quantity conservation in the $O y$ axis direction, similarly obtained for $O x(9)$ and $O z(10)$ axis.

$$
\begin{aligned}
& a_{e} v_{e}=a_{e}^{o} v_{e}^{0}+a_{s e} v_{s e}+a_{n e} v_{n e}+a_{e e} v_{e e}+a_{w} v_{w}+a_{d} v_{d}+a_{i} v_{i}+b_{e} \\
& a_{s} u_{s}=a_{s}^{0} u_{s}^{0}+a_{s s} u_{s s}+a_{n} u_{n}+a_{l} u_{l}+a_{m} u_{m}+a_{h} u_{h}+a_{j} u_{j}+b_{s}
\end{aligned}
$$

$a_{t} w_{t}=a_{t}^{0} w_{t}^{0}+a_{s t} w_{s t}+a_{n t} w_{n t}+a_{c} w_{c}+a_{k} w_{k}+a_{t t} w_{t t}+a_{b} w_{b}+b_{t}$

Following the discretization of the heat conservation equation is resulted eq. (11):

$$
a_{P} T_{P}=a_{P}^{0} T_{P}^{0}+a_{S} T_{S}+a_{N} T_{N}+a_{E} T_{E}+a_{W} T_{W}+a_{T} T_{T}+a_{B} T_{B}(11)
$$

\subsection{Stabilization of the speed correction equation}

The momentum equations are discretized as follows:

$$
\left\{\begin{array}{c}
a_{s} u_{s}=a_{s}^{0} u_{s}^{0}+a_{s s} u_{s s}+a_{n} u_{n}+a_{l} u_{l}+a_{m} u_{m}+a_{h} u_{h}+a_{j} u_{j}+b_{s} \\
a_{e} v_{e}=a_{e}^{0} v_{e}^{0}+a_{s e} v_{s e}+a_{n e} v_{n e}+a_{e e} v_{e e}+a_{w} v_{w}+a_{d} v_{d}+a_{i} v_{i}+b_{e} \\
a_{t} w_{t}=a_{t}^{0} w_{t}^{0}+a_{s t} w_{s t}+a_{n t} w_{n t}+a_{c} w_{c}+a_{k} w_{k}+a_{t t} w_{t t}+a_{b} w_{b}+b_{t}
\end{array}\right.
$$

Resolution of discretized equations is possible only if the pressure field is given or estimated. If this pressure field is incorrect, the continuity equation cannot be obtained by the speed field given by the momentum equations.

Components of an imperfect speed field (momentum equations with an estimated $p^{*}$ pressure field) are noted with $u^{*}, v^{*}$ and $w^{*}[20]$. The following discretized equations had as a solution this “*” speed field, as follows:

$$
\left\{\begin{array}{c}
a_{s} u_{s}^{*}=a_{s}^{0} u_{s}^{0}+a_{s s} u_{s s}^{*}+a_{n} u_{n}^{*}+a_{l} u_{l}^{*}+a_{m} u_{m}^{*}+a_{h} u_{h}^{*}+a_{j} u_{j}^{*}+b_{s}+\left(p_{P}^{*}-p_{s}^{*}\right) d y d z \\
a_{e} v_{e}^{*}=a_{e} v_{e}^{0}+a_{s e} v_{s e}^{*}+a_{n e} v_{n e}^{*}+a_{e e} v_{e e}^{*}+a_{w} v_{w}^{*}+a_{d} v_{d}^{*}+a_{i} v_{i}^{*}+b_{e}+\left(p_{P}^{*}-p_{E}^{*}\right) d x d z \\
a_{t} w_{t}^{*}=a_{t}^{0} w_{t}^{0}+a_{s t} w_{s t}^{*}+a_{n t} w_{n t}^{*}+a_{c} w_{c}^{*}+a_{k} w_{k}^{*}+a_{t t} w_{t t}^{*}+a_{b} w_{b}^{*}+b_{t}+\left(p_{P}^{*}-p_{T}^{*}\right) d x d y
\end{array}\right.
$$

obtained from the discretization equations of the moment, in which the terms containing the pressure forces, and thus the free terms $b_{s}, b_{e}$ and $b_{t}$, were highlighted, and became $b_{s}=0, \quad b_{e}=0, \quad b_{t}=-g \rho_{t} \beta\left(T_{t}-T_{0}\right) V$

The field of stellar speeds must satisfy the continuity equation, in this case $p^{*}$ must be modified until it does not satisfy this condition. The correct pressure $p$ is obtained with relation [20]:

$$
p=p^{*}+p^{\prime}
$$

where $p^{\prime}$ is the pressure correction. Modification of the pressure value induces a change in the speed components in the form of:

$$
\left\{\begin{array}{c}
u=u^{*}+u^{\prime} \\
v=v^{*}+v^{\prime} \\
w=w^{*}+w^{\prime}
\end{array}\right.
$$

where $u, v$ and $w$ are the correct speed components, and $u^{\prime}, v^{\prime}$ and $w^{\prime}$ are the speed corrections. Subtracting in turn equations (15) from equations (12) we obtained: 
$\left\{\begin{array}{c}a_{s} u_{s}^{\prime}=a_{s s} u_{s s}^{\prime}+a_{n} u_{n}^{\prime}+a_{l} u_{l}^{\prime}+a_{m} u_{m}^{\prime}+a_{h} u_{h}^{\prime}+a_{j} u_{j}^{\prime}+\left(p_{P}^{\prime}-p_{S}^{\prime}\right) A_{s} \\ a_{e} v_{e}^{\prime}=a_{s e} v_{s e}^{\prime}+a_{n e} v_{n e}^{\prime}+a_{e e} v_{e e}^{\prime}+a_{w} v_{w}^{\prime}+a_{d} v_{d}^{\prime}+a_{i} v_{i}^{\prime}+\left(p_{P}^{\prime}-p_{E}^{\prime}\right) A_{e} \\ a_{t} w_{t}^{\prime}=a_{s t} w_{s t}^{\prime}+a_{n t} w_{n t}^{\prime}+a_{c} w_{c}^{\prime}+a_{k} w_{k}^{\prime}+a_{t t} w_{t t}^{\prime}+a_{b} w_{b}^{\prime}+\left(p_{P}^{\prime}-p_{T}^{\prime}\right) A_{t}\end{array}\right.$

where relations (14) and (15) where taken into account, and: $A_{s}=d y d z, A_{e}=d x d z, A_{t}=d x d y$

For the calculation of speed corrections obtained with equations (16) we used the SIMPLE procedure. The method is called semi-default because the terms containing speed corrections from the neighboring grid points are omitted, thus the correction speeds became:

$\left\{\begin{array}{l}a_{s} u_{s}^{\prime}=\left(p_{P}^{\prime}-p_{S}^{\prime}\right) A_{s} \\ a_{e} v_{e}^{\prime}=\left(p_{P}^{\prime}-p_{E}^{\prime}\right) A_{e} \\ a_{t} w_{t}^{\prime}=\left(p_{P}^{\prime}-p_{T}^{\prime}\right) A_{t} \quad(17) \quad \text { or }\end{array} \quad\left\{\begin{array}{l}u_{s}^{\prime}=d_{s}\left(p_{P}^{\prime}-p_{S}^{\prime}\right) \\ v_{e}^{\prime}=d_{e}\left(p_{P}^{\prime}-p_{E}^{\prime}\right) \\ w_{t}^{\prime}=d_{t}\left(p_{P}^{\prime}-p_{T}^{\prime}\right)\end{array}\right.\right.$

where we noted: $d_{s}=\frac{A_{s}}{a_{s}}, \quad d_{e}=\frac{A_{e}}{a_{e}}, \quad d_{t}=\frac{A_{t}}{a_{t}}$

Correct speeds are given by:

$$
\left\{\begin{array}{l}
u_{s}=u_{s}^{*}+d_{s}\left(p_{P}^{\prime}-p_{S}^{\prime}\right) \\
v_{e}=v_{e}^{*}+d_{e}\left(p_{P}^{\prime}-p_{E}^{\prime}\right) \\
w_{t}=w_{t}^{*}+d_{t}\left(p_{P}^{\prime}-p_{T}^{\prime}\right)
\end{array}\right.
$$

\subsection{Establishing the correct pressure equation}

The continuity equation (4) was integrated on the control volume centered in point $P$ (Fig. 4), obtaining:

$\left(\rho_{p}-\rho_{p}^{o}\right) \frac{V}{d t}+\left[(\rho u)_{s}-(\rho u)_{n}\right] d y d z+\left[(\rho v)_{e}-(\rho v)_{w}\right] d x d z+\left[(\rho w)_{t}-(\rho w)_{b}\right] d x d y=0$

By substituting the corrected speeds, relations (19) in equation (20) we obtain:

$\left(\rho_{P}-\rho_{P}^{o}\right) \frac{V}{d t}+\left[\left(\rho u^{*}\right)_{s}+\rho_{s} d_{s}\left(p_{P}^{\prime}-p_{S}^{\prime}\right)-\left(\rho u^{*}\right)_{n}-\rho_{n} d_{n}\left(p_{N}^{\prime}-p_{P}^{\prime}\right)\right] d y d z+$

$+\left[\left(\rho v^{*}\right)_{e}+\rho_{e} d_{e}\left(p_{P}^{\prime}-p_{E}^{\prime}\right)-\left(\rho v^{*}\right)_{w}-\rho_{w} d_{w}\left(p_{W}^{\prime}-p_{P}^{\prime}\right)\right] d x d+$

$+\left[\left(\rho w^{*}\right)_{t}+\rho_{t} d_{t}\left(p_{P}^{\prime}-p_{T}^{\prime}\right)-\left(\rho w^{*}\right)_{b}-\rho_{b} d_{b}\left(p_{B}^{\prime}-p_{P}^{\prime}\right)\right] d x d y=0$

and regrouping the terms we have:

$$
a_{p} p_{p}^{\prime}=a_{s} p_{S}^{\prime}+a_{N} p_{N}^{\prime}+a_{E} p_{E}^{\prime}+a_{W} p_{W}^{\prime}+a_{T} p_{T}^{\prime}+a_{B} p_{S}^{\prime}+b
$$

where we noted:

$$
\begin{aligned}
& a_{S}=\rho_{s} d_{s} d y d z, a_{N}=\rho_{n} d_{n} d y d z, a_{E}=\rho_{e} d_{e} d x d z \\
& a_{W}=\rho_{w} d_{w} d x d z, a_{T}=\rho_{t} d_{t} d x d y, a_{B}=\rho_{b} d_{b} d x d y \\
& a_{P}=a_{S}+a_{N}+a_{E}+a_{W}+a_{T}+a_{B} \\
& b=\left(\rho_{P}^{0}-\rho_{P}\right) \frac{V}{d t}+\left[\left(\rho u^{*}\right)_{n}-\left(\rho u^{*}\right)_{s}\right] d y d z+\left[\left(\rho v^{*}\right)_{w}-\left(\rho v^{*}\right)_{e}\right] d x d z+\left[\left(\rho w^{*}\right)_{b}-\left(\rho w^{*}\right)_{t}\right] d x d y
\end{aligned}
$$

It should be noted that, although the notations of the coefficients resemble the notations used in the discretization of the heat conservation equation, here they have a completely different meaning (pressure).

In this context we have seen a lot of interests in the literature about the experimental and theoretical investigation of the heat pipes. [25-28]

\section{Results and discussion}

For the analysis of the flow and heat transfer phenomena in the upper compartment was used a spatial grid with steps $d x=d y=0.002 \mathrm{~m}$ and $d z=0.004 \mathrm{~m}$, resulting a number of $\mathrm{im} \times \mathrm{jm} \times \mathrm{km}=383 \times 46 \times 78=1374204$ computational cells. But observing that the vertical median plane - perpendicular on the wall that contains input and output orifices from the upper compartment parallel with lateral walls, is a symmetry plane, number of computational cells was reduced in half by replacing $j m=46 \mathrm{cu} j m=23$, resulting a number of 687102 cells.

Required temperatures: lower wall of upper compartment $t_{\text {inf }}=29^{\circ} \mathrm{C}$, wall of heat pipes at constant temperature of $t_{\text {pipe }}=32^{\circ} \mathrm{C}$. To take account of heat losses at the interface with the environment, an additional layer of air was added near the lateral faces and the upper face of the compartment, with a constant temperature of $t_{\text {air }}=$ $22^{\circ} \mathrm{C}$.

Thermophysical characteristics of materials that are part of the upper compartment are shown in Table 1.

Table 1. Thermophysical characteristics of materials

\begin{tabular}{|l|l|}
\hline \multicolumn{1}{|c|}{ Thermophysical characteristic } & \multicolumn{1}{c|}{ Value } \\
\hline Water density, $\rho_{\text {water }}$ & $977 \mathrm{~kg} / \mathrm{m}^{3}$ \\
\hline Specific heat of water, $c_{\text {water }}$ & $4180 \mathrm{~J} / \mathrm{kg}^{\circ} \mathrm{C}$ \\
\hline $\begin{array}{l}\text { Thermal conductivity coefficient of water, } \\
k_{\text {water }}\end{array}$ & $0.61 \mathrm{~W} / \mathrm{m}^{\circ} \mathrm{C}$ \\
\hline Cinematic water viscosity, $\mu$ & $0.8 \times 10^{-6} \mathrm{~m}^{2} / \mathrm{s}$ \\
\hline Thermal expansion coefficient of water, $\beta$ & $0.000207^{\circ} \mathrm{C}^{-1}$ \\
\hline Steel density, $\rho_{\text {steel }}$ & $7800 \mathrm{~kg} / \mathrm{m}^{3}$ \\
\hline Specific heat of steel, $c_{\text {steel }}$ & $630 \mathrm{~J} / \mathrm{kg}{ }^{\circ} \mathrm{C}$ \\
\hline $\begin{array}{l}\text { Thermal conductivity coefficient of steel, } \\
\boldsymbol{k}_{\text {steel }}\end{array}$ & $60 \mathrm{~W} / \mathrm{m}^{\circ} \mathrm{C}$ \\
\hline Copper density, $\rho_{\text {copper }}$ & $8920 \mathrm{~kg} / \mathrm{m}^{3}$ \\
\hline Specific heat of copper $c_{\text {copper }}$ & $390 \mathrm{~J} / \mathrm{kg}{ }^{\circ} \mathrm{C}$ \\
\hline $\begin{array}{l}\text { Thermal conductivity coefficient } \text { of } \\
\text { copper, } k_{\text {copper }}\end{array}$ & $399 \mathrm{~W} / \mathrm{m}{ }^{\circ} \mathrm{C}$ \\
\hline Speed of water input, $v_{w . i .}$ & $0.27 \mathrm{~m} / \mathrm{s}$ \\
\hline
\end{tabular}

Values of the parameters used for the initial conditions are shown in Table 2. Two runs were performed and for each of them the initial condition varied: 
Table 2. Initial conditions used for each run.

\begin{tabular}{|c|c|c|c|c|c|}
\hline $\begin{array}{c}\text { Run } \\
\text { no. }\end{array}$ & $\begin{array}{c}\mathbf{D}_{\mathbf{0}} \\
{\left[\mathbf{m}^{\mathbf{3}} / \mathbf{h}\right]}\end{array}$ & $\begin{array}{c}\mathbf{v}_{\text {w.i. }} \\
{[\mathbf{m} / \mathbf{s}]}\end{array}$ & $\begin{array}{c}\mathbf{t}_{\text {tair }} \\
{\left[{ }^{\circ} \mathbf{C}\right]}\end{array}$ & $\begin{array}{c}\mathbf{t}^{\prime}{ }_{\mathbf{2}} \\
{\left[{ }^{\circ} \mathbf{C}\right]}\end{array}$ & $\begin{array}{c}\mathbf{t}^{\prime} \mathbf{1} \\
{\left[{ }^{\circ} \mathbf{C}\right]}\end{array}$ \\
\hline 1. & 0.37 & 0.083 & 22 & 12 & 35 \\
\hline 2. & 1.18 & 0.261 & 27 & 22 & 60 \\
\hline
\end{tabular}

The runs were conducted with a variable time step, determined based on the maximum flow speed at the beginning of each cycle.

The flow divider in the upper compartment has the purpose of increasing the heat exchanger's efficiency, because the main flow passes twice between the condensing sides of the heat pipes [11], thus the cold water will accumulate a larger amount of heat - in a given interval of time.

Figure $8 a$ ) and b) presents the position of the free surface in vertical transversal sections close to the input orifice, at $10 \mathrm{~mm}$ from the wall with the input orifice, and in the section that contains the first two heat pipes. We can see the partially filled cells and the formation of swirling currents near the walls, centered in points $A$ and $B$. Also, there are swirling currents formed between pipes and lateral walls.
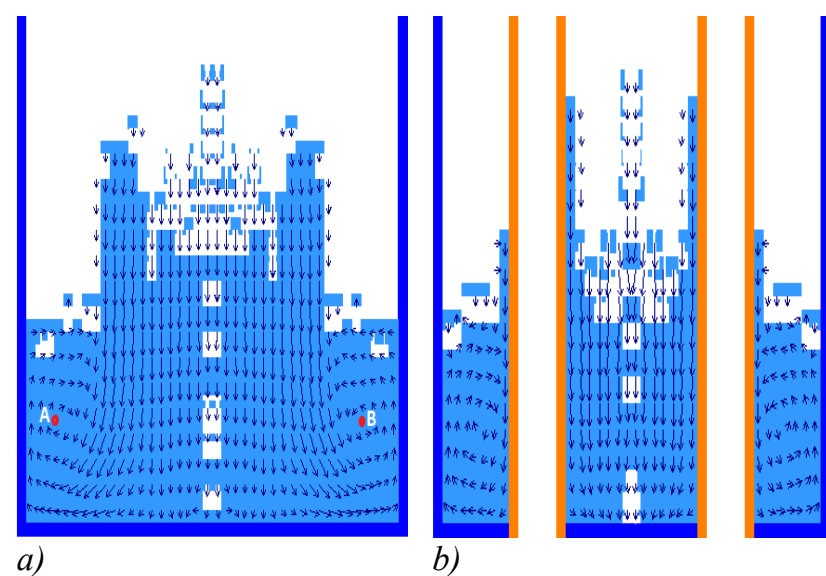

a)

Fig. 8. Position of the free surface, at $t=0.24 s, v_{w . i .}=0.083$ $\mathrm{m} / \mathrm{s} . \mathrm{a}$ ) in vertical transversal section, at $10 \mathrm{~mm}$ from the wall with the input orifice and $b$ ) in section that contains the first two heat pipes near the input orifice.

Results obtained from running the program, in which the heat exchange is taken into account, are presented below.

In Figure 9 is presented the distribution of temperature in the central vertical section at $t=168 \mathrm{~s}$ from the beginning of operation of the heat exchanger and at $t^{\prime}{ }_{1}=35^{\circ} \mathrm{C}, t^{\prime}{ }_{2}=12^{\circ} \mathrm{C}, t_{\text {air }}=22^{\circ} \mathrm{C}, v_{w . i .}=0.083$ $\mathrm{m} / \mathrm{s}$. Near the lateral walls, the upper wall and in the flow divider plate, the temperature is lower, with values between $13-15^{\circ} \mathrm{C}$. Near the inferior wall, in contact with the lower compartment and heat pipes, there is a warm layer with temperatures of $25-27^{\circ} \mathrm{C}$. Inside, there are warmer traces next to the heat pipes. At the left end of the divider plate there is a deformation of these traces, due to a swirling current formed in this phase of operation of the heat exchanger.

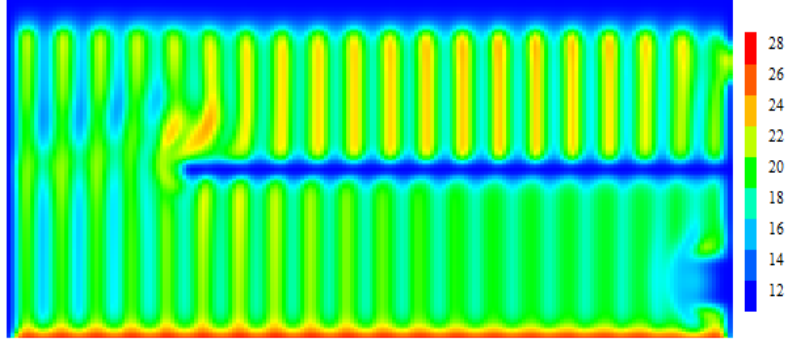

Fig. 9. Distribution of temperature in the central vertical section.

In Figure 10 is shown the intensity of speeds, in horizontal section made a distance of $2 \mathrm{~cm}$ from the inferior wall. We can see the main current between the 2 rows of pipes, with maximum speeds in the center of the section, slowing of the flow towards the lateral wall opposed to the input. Speed intensity is lower between two consecutive pipes, but also near the central area of the lateral walls.

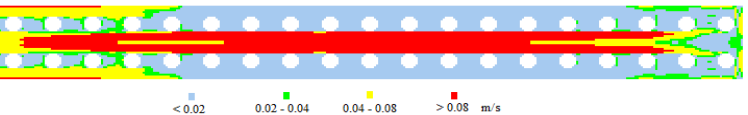

Fig. 10. Intensity of the flow speeds.

Temperature of the preheated water outputting the upper compartment was obtained by a mean of the temperature values in the computational cells, which represent the input sections, namely:

$$
T_{\text {output }}(t)=\frac{\sum_{i, j, k \in D_{\text {evac }}} T[i, j, k]}{N}
$$

where: $T_{\text {output }}$ is the temperature in the evacuation section; $D_{\text {evac }}$ is the domain formed by cells that are part of the evacuation section; $t$ is time that passed since the beginning of operation of the heat exchanger; $N$ is the number of computational cells in the evacuation section.

$T_{i e s}(t)$ values were saved every step of time and based on these values were constructed graphs of temperature evolution in the evacuation section. In analogy, was determined the mean pressure in the input sections $p_{\text {input }}$ and in the evacuation sections $p_{\text {output }}$, in order to determine the pressure drop between the input orifice and the evacuation orifice:

$$
\Delta p=p_{\text {input }}-p_{\text {output }}
$$

In Figure 11 are presented the variation of temperatures of preheated water, at the output orifice from the upper compartment. We can observe that time required to obtain a state of quasi-stationary state depends of the input speed, initial temperature of the cold water and temperature of the environment. In this figure we can observe how the cold water temperature varies depending on time at the output orifice of the upper compartment in the case of the first run.

Due to the heat insulating paint applied on the lateral and upper walls, the heat exchange coefficient between the walls and the environment have a relatively low 
value of $2 \mathrm{~W} / \mathrm{m}^{2}{ }^{\circ} \mathrm{C}$. At lower input speeds, the quasistationary phase is obtained later. Similarly, at lower environment temperatures, the time required to obtain the quasi-stationary state increases.

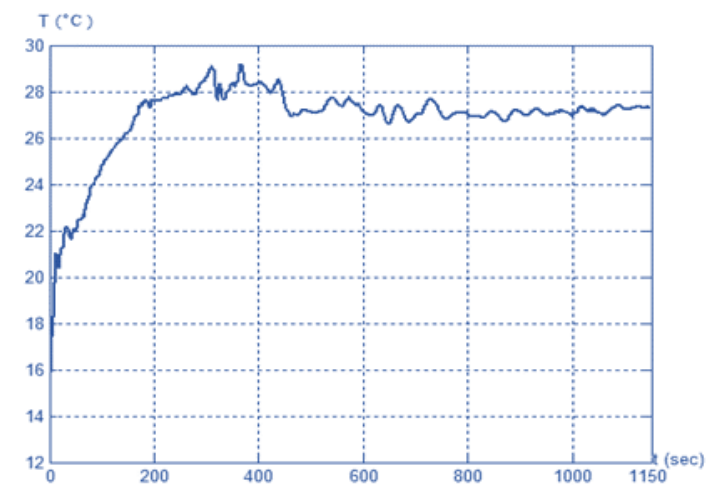

a)

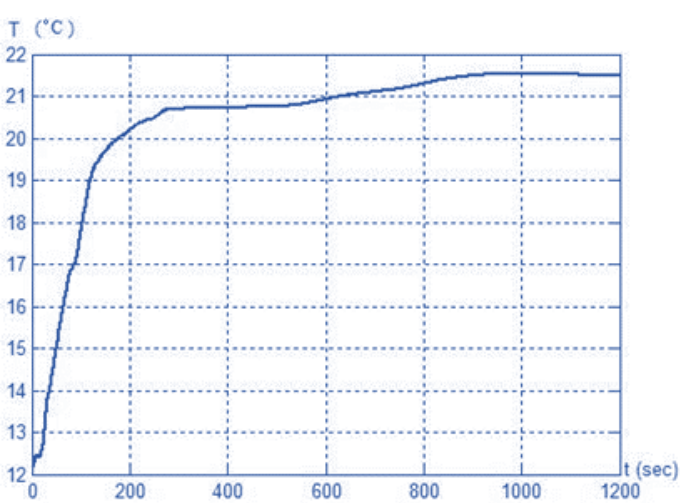

b)

Fig. 11. Variation of temperature of heated water at the output orifice: $a$ ) first run; $b$ ) second run.

A centralization of the values obtained for temperature during the two runs, is shown in Table 3. Results obtained for the estimated efficiency are presented in this table based on relation [29].

$$
\varepsilon_{\text {estimated }}=\frac{t_{2}^{\prime \prime}-t_{2}^{\prime}}{t_{1}^{\prime}-t_{2}^{\prime}} \cdot 100 \%
$$

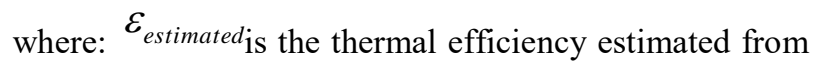
the computer simulation; $t_{2}^{\prime \prime}$ is the temperature in the evacuation section; $t_{2}^{\prime}$ is the temperature of cold water at the input orifice; $t_{1}^{\prime}$ is the temperature of wastewater at the input.

Table 3. Values obtained after running the program.

\begin{tabular}{|c|c|c|c|c|c|c|c|}
\hline $\begin{array}{c}\text { Run } \\
\text { no. }\end{array}$ & $\begin{array}{c}\mathbf{V}_{\text {w.i. }} \\
{[\mathbf{m} / \mathbf{s}]}\end{array}$ & $\begin{array}{c}\text { tair } \\
{\left[{ }^{\circ} \mathbf{C}\right]}\end{array}$ & $\begin{array}{c}\mathbf{t}^{\prime} \mathbf{2} \\
{\left[{ }^{\circ} \mathbf{C}\right]}\end{array}$ & $\begin{array}{c}\mathbf{t}^{\prime} \mathbf{1} \\
{\left[{ }^{\circ} \mathbf{C}\right]}\end{array}$ & $\begin{array}{c}\mathbf{t}^{\prime \prime} \mathbf{2} \\
{\left[{ }^{\circ} \mathbf{C}\right]}\end{array}$ & $\begin{array}{c}\Delta \mathbf{p} \\
{[\mathbf{P a}]}\end{array}$ & $\begin{array}{c}\text { Eestim } \\
{[\mathbf{\%} \mathbf{0}]}\end{array}$ \\
\hline 1. & 0.083 & 22 & 12 & 35 & 27.6 & 1931.8 & 68 \\
\hline 2. & 0.261 & 27 & 22 & 60 & 34.11 & 1962.5 & 32 \\
\hline
\end{tabular}

We can observe that a maximum efficiency was obtained for run number one, and the lowest efficiency for run number two. The cause of low efficiency for run number two is high input speed, which reduces the contact time of cold water with the heat pipes.

\section{Conclusions}

The program used in the heat and mass transfer simulation was done in the Delphi 7 programming language, which is a variant of the Turbo Pascal language. This program contained a series of subprograms for discretization of the domain occupied by the heat exchanger with heat pipes, another subprogram for solving the discretization equations and a third one for post-processing.

Parameters for the flow and heat transfer analysis were chosen to be as close as possible to the real existing conditions, due to the fact that at an experimental level on the laboratory stand we could not use a high enough flow and due to weather conditions (cold water temperature was higher).

The results, obtained by computerized simulation, revealed that the recovered temperature depends greatly on the flow of wastewater and cold water, which validates the experimental results.

Also, the obtained results revealed that the distribution of speed field inside the upper compartment, between the heat pipes, leads to the formation of swirls, where the heat transfer is much lower, due to the way in which the placement of pipes that are in line.

In the context of the above, we can conclude that heat recovery from wastewater in quasi-stationary regime depends on: the speed of the input cold water, the initial temperature of the cold water and the temperature of the environment, which was confirmed by the conducted experimental research.

\section{Acknowledgements}

The results presented in this paper were obtained with the support of the Technical University of Cluj-Napoca. Through the research Contract no. 1994/12.07.2017, CI_2017_IMM_1, Internal Competition CICDI-2017.

\section{References}

1. A. Hepbasli, E. Biyik, O. Ekren, H. Gunerhan, M. Araz, J. Energy Conversion and Management 88, pp. 700-722 (2014)

2. A.R. Mazhar, S. Liu, A. Shukla, J. Energies 11, 386, pg. 34. (2018)

3. A. Balastov, N. Kachalov, E. Senkiv, O. Kachalova, J. MATEC Web of Conferences 110, 01008 (2017)

4. M. Omidi, M. Farhadi, M. Jafari, J. Applied Thermal Engineering 110, pp. 1075-1090 (2017)

5. O. Culha, H. Gunerhan, E. Biyik, O. Ekren A. Hepbasli, J. Energy and Buildings 104, pp. 215232 (2015)

6. A. Matveev, D. Zelentsov, A. Louks, J. MATEC Web of Conferences 106, 06016 (2017)

7. S. Ornelas, S. Sousa, C. Dong, M. Fernelius, M. Hofer, T. Holsclaw, A. Jennison, D. Mai, K. Ninh, 
M. Poel, Mathematical modeling, numerical simulation and statistical optimization of heat pipe design, (Report of Center for Applied Mathematics, Computation and Statistics Departament of Mathematics, San Jose, CA, pp. 1-37, 2006)

8. M.I. Heredia, J. Siqueiros, J.A. Hernández, D. Juárez-Romero, A. Huicochea, J.G. GonzálezRodríguez, J. Applied Thermal Engineering 128, pp. 737-746 (2018)

9. H. Ma, L. Yin, X. Shen, W. Lu, Y. Sun, Y. Zhang, N. Deng, J. Applied Energy 169, pp. 177-186 (2016)

10. A. Nouri-Borujerdi, M. Layeghi, J. Fluids Engineering, 126, pp. 442-448 (2004)

11. S. Knudsen, G.L. Morrison, M. Behnia, S. Furbo, J. Solar Energy, 78, 2, pp. 281-289 (2005)

12. S.F. Tsai, T.W.H. Sheu, J. Computers \& Fluids, 27, 1, pp. 29-46 (1998)

13. D.J. Durrenmatt, O. Wanner, J. Water Research 48, pp. 548 - 558 (2014)

14. Gupta M, Numerical Study of Heat Transfer Enhancement in a Plate-Fin Heat Exchanger Using Rectangular Winglet Type Vortex Generator (Ph.D. Thesis, National Institute of Technology, Kurukshetra, India, 2010)

15. Khan W.A, Modeling of Fluid Flow and Heat Transfer for Optimization of Pin-Fin Heat Sinks (Ph.D. Thesis, University of Waterloo, Canada, 2004)

16. Sahiti N, Thermale and Fluid Dynamic of Pin Fin Heat Transfer Surfaces (Ph.D. Thesis, Erlangen University, Nürnberg, Germany, 2006)

17. Williamson N.J, Numerical Modelling of Heat and Mass Transfer and Optimisation of a Natural Draft Wet Cooling Tower (Ph.D. Thesis, University of Sydney, Australia, 2008)

18. A.A. Ozalp, I.Dincer, International Journal of Thermal Sciences, 49, pp. 1799-1812 (2010)

19. N.C. Markatos, J. Ironmaking and Steelmaking, 16, 4, pp. 266-273 (1989)

20. Patankar S.V, Numerical Heat Transfer and Fluid Flow (Taylor \& Francis, New York, 1980)

21. Olsen N.B, CFD Algorithms for Hydraulic Engineering (Norvegian University of Science and Technology, Trondheim, Norway, 2000)

22. C.W. Hirt, B.D, Nichols, J. Computational Physics, 39, pp. 201-225 (1981)

23. G.Y. Soh, G.H. Yeoh, V. Timchenko, International Journal of Heat and Mass Transfer, 100, pp. 573581 (2016)

24. H-J. Laue, H. Kruse, J. Wärmepumpe Aktuell Informationszentrum Wärmepumpen + Kältetechnik, 8, 2, pg. 2 (2009)

25. Faghri A, Heat Pipe Science and Technology (Taylor \& Francis, New York, 1995)

26. X.-S. Yang, M. Karamanoglu, T. Luan, S. Koziel, J. Computational Science 5, pp. 119-125 (2014)

27. H. Jouhara, S. Almahmoud, A. Chauhan, B. Delpech, G. Bianchi, A. Tassou R. Llera, F. Lago, J.J. Arribas, J. Energy 141, pp. 1928-1939 (2017)

28. R.T. Dobson, T.M. Harms, Lumped parameter analysis of closed and open oscillatory heat pipes, (in: $11^{\text {th }}$ Int. Heat Pipe Conf. Tokyo, 12-16 September 1999)

29. Proskiw G. 2003, Design and Analysis of a Residential Greywater Heat Recovery System (Report Prepared for CANMET Energy Technology Centre, Canada, pg. 4, 5, 52, 2003) 